\title{
Alkaline Fuel Cell (AFC) engineering design, modeling and simulation for UPS provide in laboratory application
}

\author{
L. Ariyanfar ${ }^{1, *}$, H. Ghadamian ${ }^{2}$, R. Roshandel ${ }^{3}$ \\ ${ }^{1,2}$.Department of Energy Engineering, Science and Research Campus, Islamic Azad University, Tehran, IRAN \\ ${ }^{3}$. Energy Engineering Department, Sharif University of Technology, Tehran, IRAN \\ * Corresponding author. Tel: +98 21 44240042, Fax: +98 21 44232205, E-mail: Leyliariyan@gmail.com
}

\begin{abstract}
In the presented research, a feasibility study to cover a mobile electrolyte alkaline fuel cell behaviors and characteristics (which the electrolyte has system cooling role) for UPS (Uninterruptable Power Supply) application is provided to use in an energy laboratory. Electrochemical modeling and computations for irreversiblities led to optimization of cell voltage, current \& power densities and the results are found to be $0.566 \mathrm{~V}, 574.3 \mathrm{~mA} / \mathrm{cm}^{2}, 325.2 \mathrm{~mW} / \mathrm{cm}^{2}$ respectively. By using mentioned quantities, ideal thermodynamic efficiency, real thermodynamic efficiency and electrical efficiency concluded $80 \%, 38 \%$ and $34 \%$ respectively. Preliminary electrochemical studies in this research are combined with engineering designs in complementary stage of research. At the next stage, considerations on heat and mass transfer and contributed models lead to approve a double pipe heat exchanger as energy sink. Then the cost model is also determined and the optimization codes are developed to propose best operation point of system with minimizing total cost and determining the heat exchanger dimensions, flow rates and temperatures. Furthermore, parametric analysis for variation of temperature, electrolyte cooling rate and cost of planned AFC has been studied for energy efficiency and performance improvement.
\end{abstract}

Keywords: Alkaline Fuel Cell (AFC), Irreversibilities, Heat Transfer, Cost Model, Parametric Analysis.

\section{Introduction}

Fuel cell is an electrochemical system that converts energy of the chemical reaction to useful electrical energy and is made of anode, cathode and electrolyte. Fuel cells classified according to practical temperature, type of electrolyte and constitutive materials; and alkaline fuel cells or AFCs are one of low temperature systems with an alkaline solution as the electrolyte. Alkaline fuel cell is the oldest type of fuel cells, which had described in 1902 and have used in spatial applications [1]. AFC produce electricity through oxidation - reduction reactions between oxygen and hydrogen. In the fuel cell reaction water is generated, and two electrons are released. The electrons flow through an external circuit, and have returned to the cathode to reduce oxygen in an electrochemical reaction and thus hydroxide ions are produced. Electricity and heat are made as byproducts of this product [2]. This system usually has peripheral equipment. Wide studies have done about alkaline fuel cells; but what had not enough attention is specialty study with practical and all purpose approach. Although the central system produce the power, but peripheral equipment also use and effect on whole system performance and the total cost. In this research has been trying to design system and accessories in the optimal mode of increasing efficiency and reducing costs are assessed.

\section{System configuration}

An energy laboratory is designed, which part of its power provide from fuel cell systems with ancillary performance and specific aims. Several different objects in correlation with together are contemplated in this laboratory that each has its survey. The typical plan of laboratory is shown in Fig.1. As seen a 100W AFC has chosen for UPS provider of this laboratory. In these cells the electrolyte is alkaline solution and how to use of is an issue. It can be in mobile electrolyte, static electrolyte and dissolved fuel alkaline fuel cells modes [1]. What are discussed in this research are electrochemistry calculations, engineering design and heat transfer of an alkaline fuel cell system with system optimization aim. 


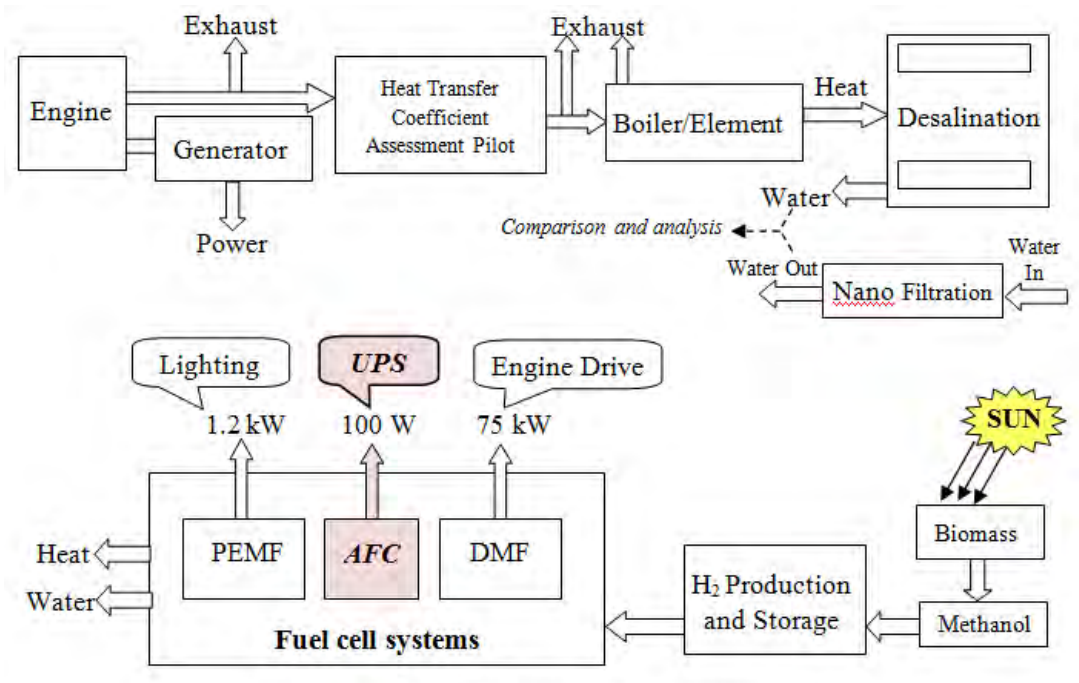

Fig. 1. Designed Energy Laboratory

Fig. 1. Designed Energy Laboratory

The basic structure design for mobile electrolyte AFC system [3] is shown in Fig.2.

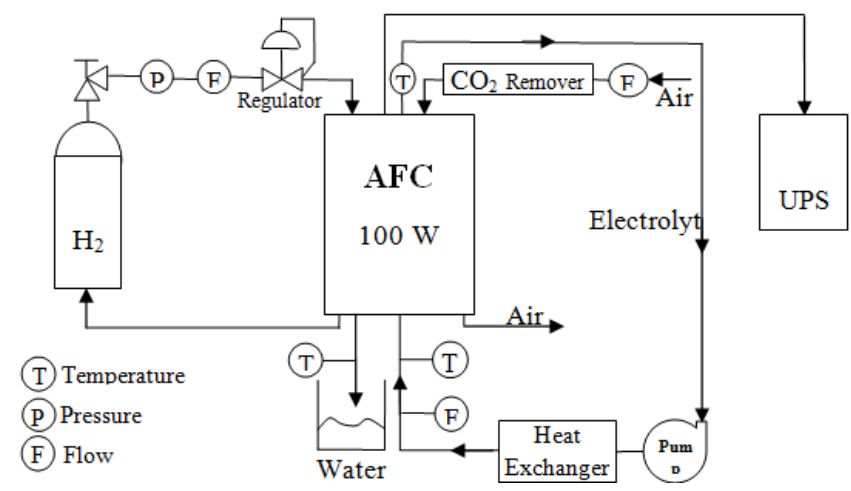

Fig. 2. Alkaline fuel cells with mobile electrolyte system and peripheral equipments

Procedures in this type of systems is so that the electrolyte flow between the anode and cathode plates in addition ion transfer and electric current; with its circulation led the excess heat of system to the outside and before re-entry into the system shall pass within a heat exchanger for cooling. Electrolyte needs pumping system us to held circulating [1].

\subsection{Electrochemistry}

According to voltage losses [4] in a fuel cell system, optimum current is achieved so that losses would be minimum, and thus optimal power and voltage are obtained $[5,6]$. Types of efficiencies that are considered in this system are ideal and actual thermodynamic efficiency and electrical efficiency that can be helpful to evaluation of system.

\subsection{Engineering design}

Hydrogen and air consumption, and water, electricity and heat production flow rates are calculated. A fuel cell stack consists of many separate cells. Design of stack and cells arrangement (after obtain the whole required surface) can has different modes. According to the desired power, energy demand and circumstances can decide regarding choice of optimized mode. 


\subsection{Heat Transfer}

In mobile electrolyte systems, the cooling process is done by electrolyte. So according to the rate of heat production in electrochemical reactions and selected materials [7,8], electrolyte flow rate can set somehow that eject the waste heat from system and kept system performance in ideal temperature [9,10]. Overall fuel cell system heat transfer can be done through conduction, convection and radiation. Since the alkaline fuel cell systems have low operation temperature, radiant heat transfer can be waivered [11].

\section{System Modeling}

To begin calculations, considering series of assumptions and initial conditions are necessary [12]. The system is considered to produce 100 watt in atmospheric pressure. It is assumed that produced water is in liquid form. Electrochemistry relations have scrutinized with optimization voltage and current using GAMS software. The optimum solution determined efficiency values and input and output flow rates. According to the steps of stack and cells arrangement [13], algorithm of Fig.3 can be used in modicum number studies.

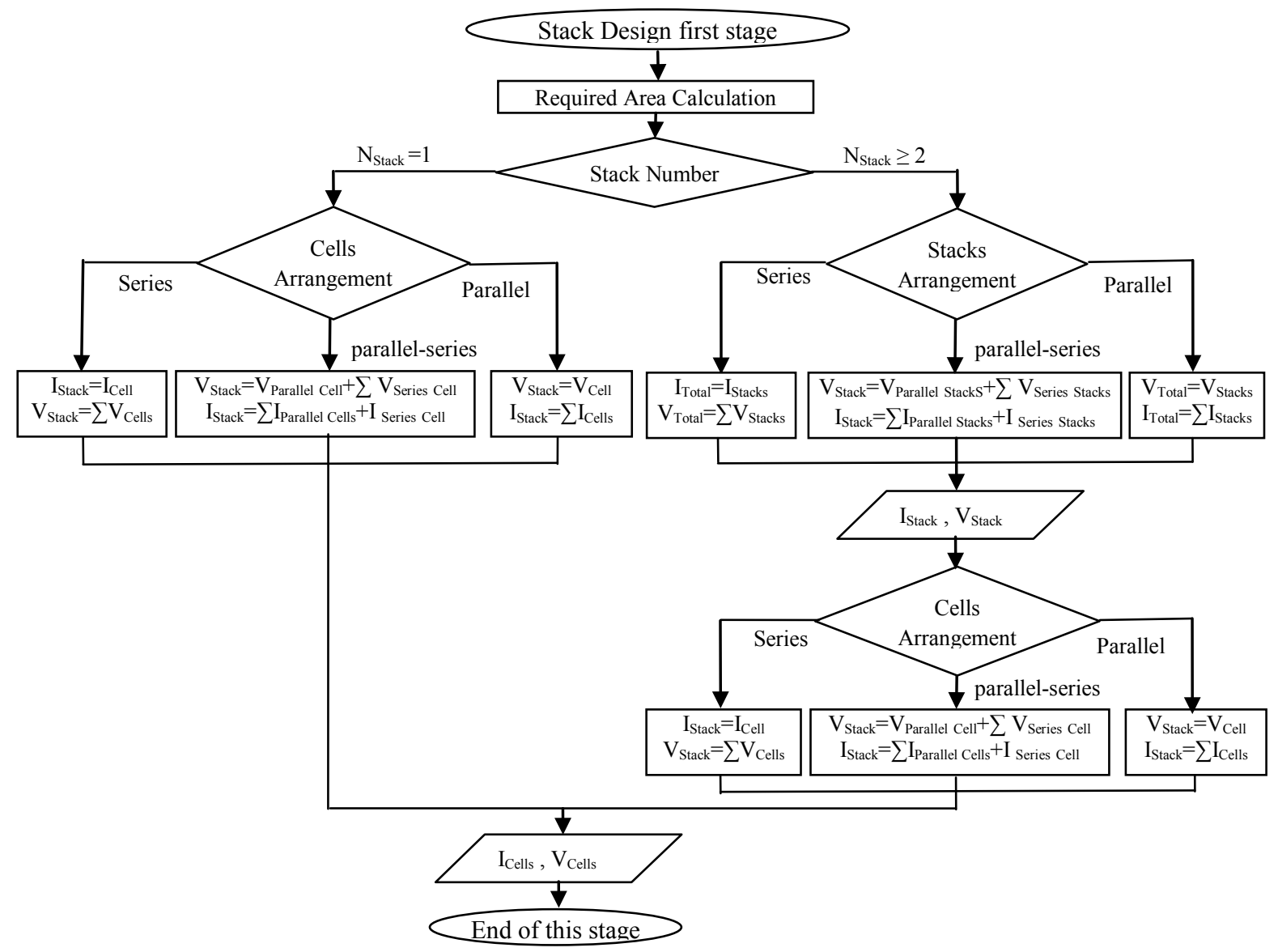

Fig. 3. Stack design algorithm

To evaluate heat transfer of system, anode, cathode and the whole of system are considered as three distinct control volumes, and heat and mass transfer relationships are extracted $[14,15]$. As noted, according to system description, a heat exchanger is required. For this purpose a double pipe heat exchanger is designed which electrolyte as the warm fluid have streaming in the inner tube and water consider as cooling fluid within the external tube [16]. In order to having a circulating electrolyte stream a proportional pump should be applied. 


\subsection{Cost model}

A mobile alkaline electrolyte fuel cell system requires peripheral equipment such as hydrogen storage tank, circulating pump to provide the electrolyte driving force, heat exchanger and series of additional process such as hydrogen production. So in addition to the fuel cell cost, there are other equipments that should be considered. Thus, if consider the computing for 1000 hours annual performance, five years of application, and 15\% inflation rate, with determining costs equation and set values also using the equations of heat transfer section and the heat exchanger design, it could be possible to optimize the overall system performance. For this purpose, GAMS code was developed, using heat transfer, heat exchanger design and the cost model equations the aim to minimize required cost to obtain the optimal heat exchanger area, rate of input and output flows and temperatures in the heat exchanger.

If design and calculation steps collect in an algorithm and associate them with each other, algorithm of Fig. 4 will be obtained:

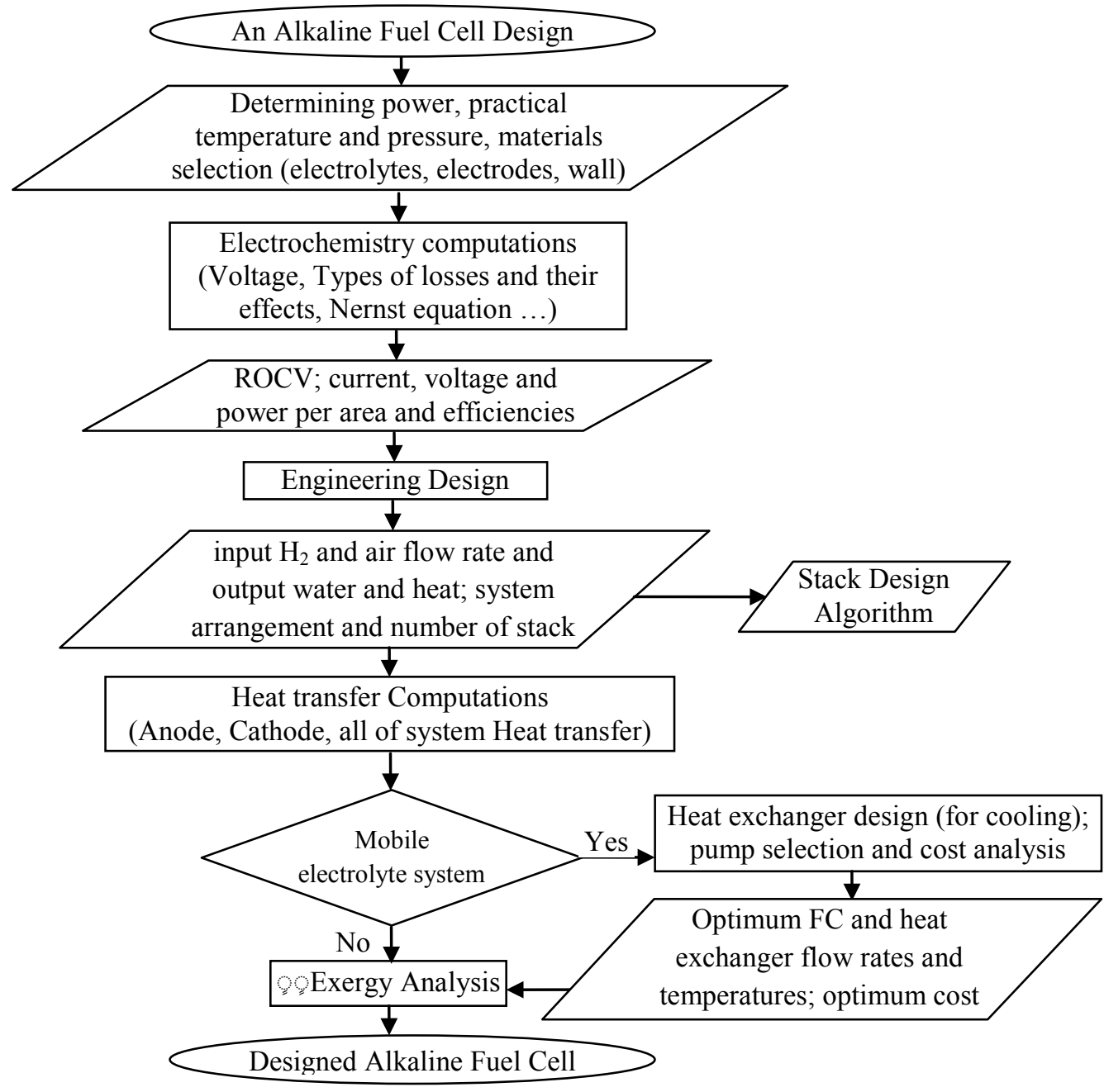

Fig. 4. Main steps of system design algorithm

\section{Results}

The results of electrochemical section and codes are presented in Table 1 and Fig.5 : 
Table 1. Optimum electrochemical results

\begin{tabular}{ccc}
\hline Voltage $(V)$ & Current Density $\left(\mathrm{mA} / \mathrm{cm}^{2}\right)$ & Power $\left(\mathrm{mW} / \mathrm{cm}^{2}\right)$ \\
\hline 0.566 & 574.316 & 325.19 \\
\hline
\end{tabular}

Required area for desired power is $308 \mathrm{~cm}^{2}$. Relation between voltage and current density [17, 18] is affected by irreversibilities and when cell current [19] increases, voltage of cell drops [20] because of activation, ohmic and mass transfer losses.

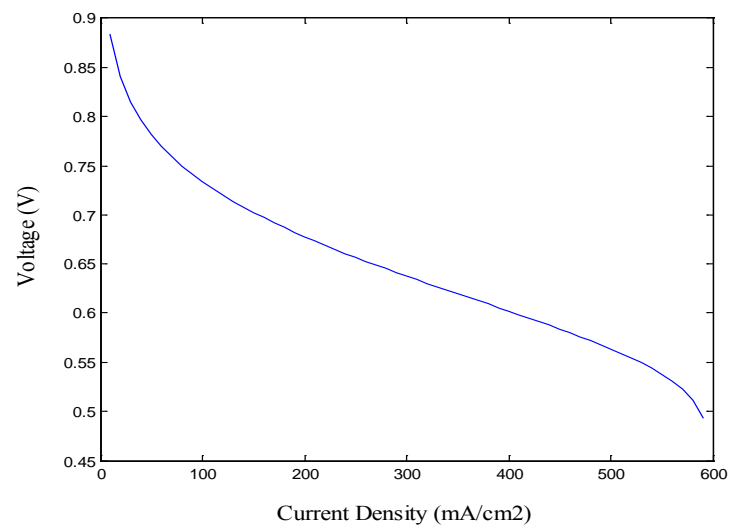

Fig.5. Voltage-Current graph

Designed system performance is presented in Table 2.

Table 2. Amount of efficiencies

\begin{tabular}{ccc}
\hline Ideal thermodynamic efficiency & Actual thermodynamic efficiency & Electrical efficiency \\
\hline $80 \%$ & $38 \%$ & $34 \%$ \\
\hline
\end{tabular}

In engineering design step inlet and outlet flow rates are calculated as Table 3.

Table 3. Electrochemical flow rates

\begin{tabular}{cccccc}
\hline Hydrogen & Oxygen & Inlet air & Outlet air & Produced water & \\
\hline $1.85 \times 10^{-6}$ & $1.48 \times 10^{-5}$ & $1.26 \times 10^{-4}$ & $1.12 \times 10^{-4}$ & $1.65 \times 10^{-10}$ & $(\mathrm{~kg} / \mathrm{s})$ \\
\hline
\end{tabular}

Also it is concluded that for $100 \mathrm{~W}$ power, overall $263 \mathrm{~W}$ energy is generated. So it is seen that power to overall energy ratio is exactly $38 \%$; and this is equal with calculated actual thermodynamic efficiency. Estimated cost for designed system in five years of operation is $2560 \$$. Obtained temperature, required area and flow rates in optimal mode are as Table 4:

Table 4. Optimum temperature, required area and flow rates

\begin{tabular}{ll}
\hline Electrolyte inlet to heat exchanger and outlet of cell temperature & $40\left({ }^{0} \mathrm{C}\right)$ \\
Mass flow rate of electrolyte & $1.6 \times 10^{-4}(\mathrm{Kg} / \mathrm{s})$ \\
Electrolyte outlet of heat exchanger and inlet to cell temperature & $73\left({ }^{0} \mathrm{C}\right)$ \\
Cold fluid mass flow rate (Water) & $2.827 \times 10^{-4}(\mathrm{Kg} / \mathrm{s})$ \\
Cold fluid outlet temperature (Water) & $25\left({ }^{0} \mathrm{C}\right)$ \\
Area of heat exchanger & $0.07\left(\mathrm{~m}^{2}\right)$ \\
Pressure drop & $5.2 \times 10^{-4}(\mathrm{~Pa})$ \\
Total Heat rate & $121.7(\mathrm{~W})$ \\
\hline
\end{tabular}

The performance of cell is under influence of different factors, such as temperature. In order to peruse the effect of temperature on cell and all of system (cell and peripheral equipment), the graphs of difference efficiencies toward temperature are depicted in Fig.6. It is found that 
because of reducing sensitivity of total system toward temperature with existing cooling section, its gradient is less than ideal performance of cell.

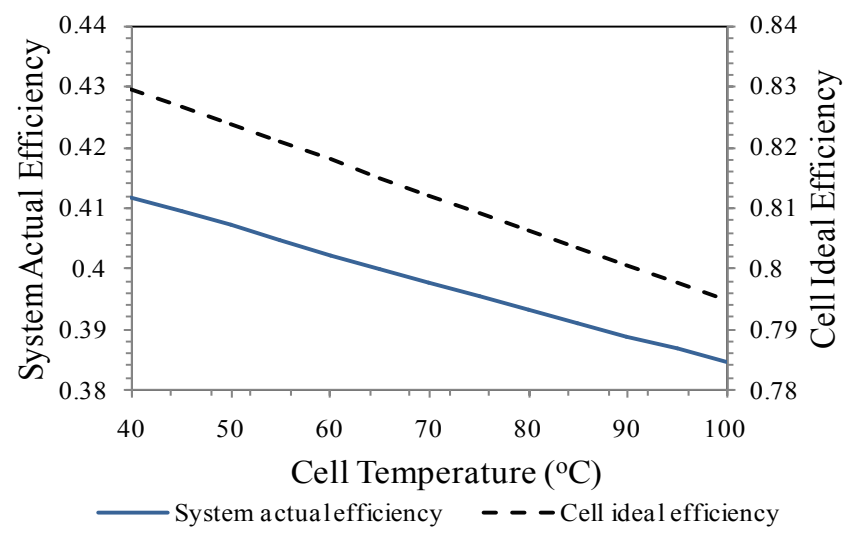

Fig. 6. Difference efficiency toward performance temperature

Nether graph is depicted to survey the effect of parameters variations toward electrolyte outlet temperature from AFC. As seen in Fig.7, with increasing temperature, flow rate of electrolyte and its pressure drop that depend on circulating flow rate, moreover the actual efficiency of system, are decreased. However, required heat exchanger area increases; because it should cool the warmer electrolyte. The minimum value of system total cost, which is obtained from system optimization GAMS codes, has been shown in this graph.

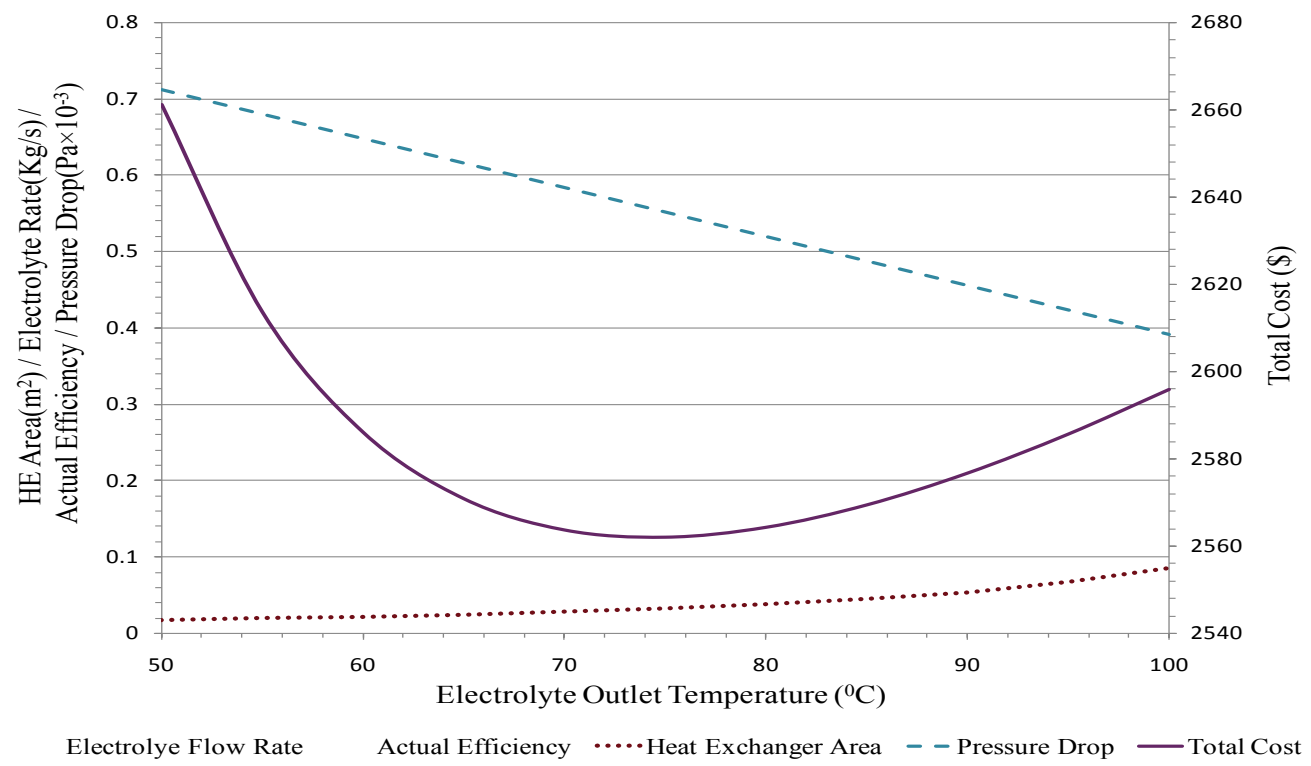

Fig. 7. Change of parameters toward electrolyte outlet temperature

Considering the gradient of cost in Fig.7, by temperature reducing before minimum cost, increasing of cost is more strongly; But after minimum cost by rising of temperature cost increasing is milder; And this suggests that circulating system is more effective than cooling system on total cost (Fig.8 confirm this matter, too).

Fig.8 is depicted to survey parameters variations toward electrolyte inlet temperature to AFC. As seen, with increasing temperature, flow rate of electrolyte and its pressure drop increase; because the electrolyte with increasing the circulation rate can compensate additional heat. Similar to Fig.7, increasing temperature of cell has led to decrease the actual efficiency of 
system. Also required heat exchanger area is decreased; because it does not need to cool electrolyte to lower temperature and it needs lesser area.

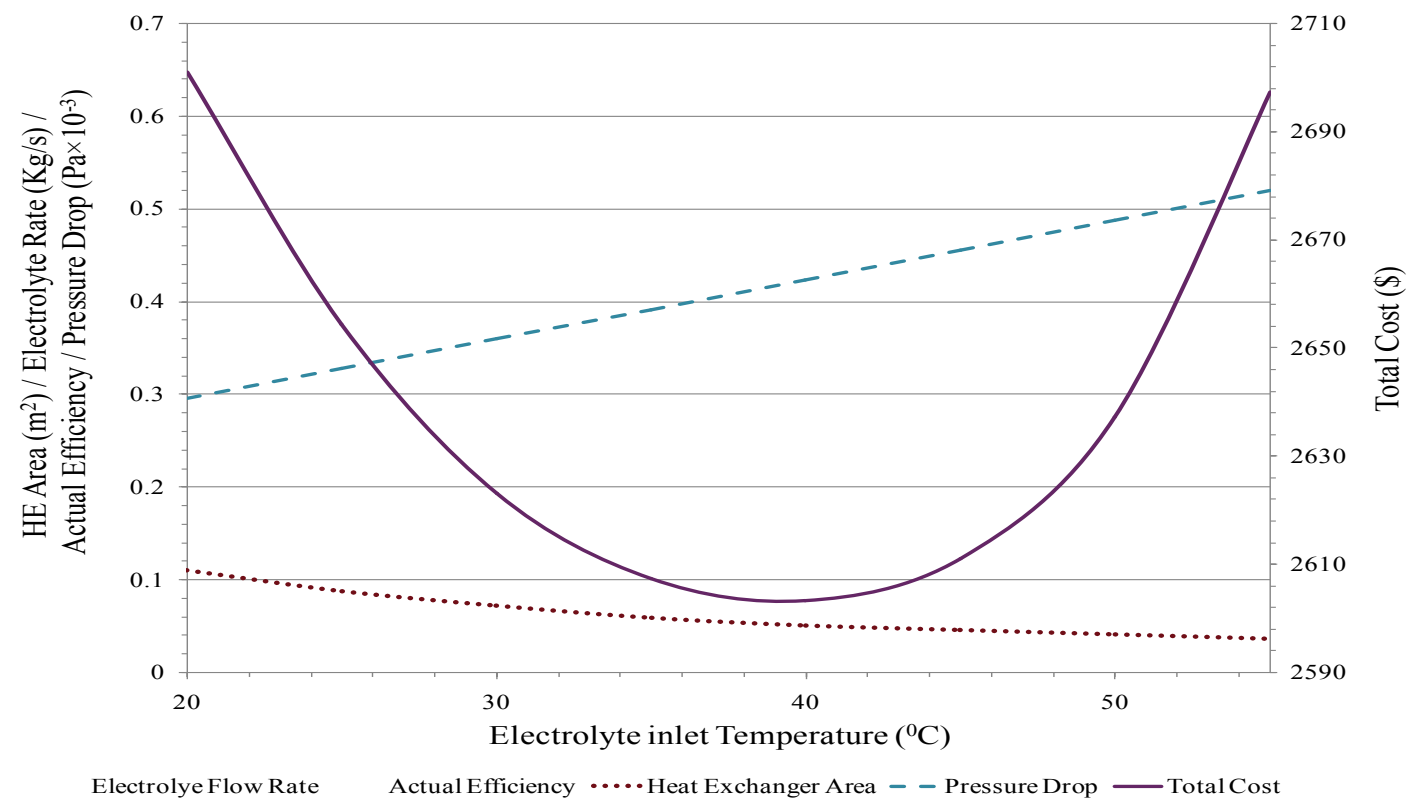

Fig. 8. Change of parameters toward electrolyte inlet temperature

According to the influential parameters plotted in the graphs and change quantities, from it is seen quality viewpoint that priority of items that effect the composite AFC system are for electrolyte pressure drop, electrolyte flow rate and heat exchanger area, respectively and two first items are running cost type, and third item is fixed cost type.

In Fig.7 and Fig.8, the effect of electrolyte input and output temperatures have been evaluated, hence with combining them the effect of $\Delta \mathrm{T}$ changes can be deduced. Except actual efficiency of system, the changes sense is same with flow rate, pressure drop, heat exchanger area at all values, and also with total cost before and after the minimum point.

\section{Conclusions}

In the presented research, a $100 \mathrm{~W}$ alkaline fuel cell with mobile electrolyte and its peripheral equipment have been designed in determined steps to achieve a design model. Presented model has been optimized using GAMS codes to find optimum values of cost model, electrochemical and heat transfer equations.

It was concluded that electrolyte flow rate and its inlet and outlet temperatures, pressure drop, heat exchanger area are some of parameters that effect on cell performance and total cost. Also the efficiency of system reduces toward temperatures rising.

Change of total cost is more sensitive toward input electrolyte temperature rather than output electrolyte temperature. Because input flow controls by peripheral systems; but outlet temperature is a function of fuel cell operation.

Also it was found that running cost is more effective parameter than the fixed cost, in the total cost of systems with similar capacity.

\section{References}

[1] J. Larminie, A. Dicks, Fuel Cell Systems Explained, Second Edition, 2002. 
[2] M.C. Williams, EG\&G Technical Services, Fuel Cell Handbook, Seventh Edition, 2004.

[3] E. Brillas, F. Alcaide, P. Cabot, A small-scale flow alkaline fuel cell for on-site production of hydrogen peroxide, Journal of Electrochimica Acta, 2002.

[4] M. Shen, K. Scott, Power loss and its effect on fuel cell performance, Journal of Power Sources, 2005.

[5] H. ghadamian, Quantitative analysis of irreversibilities causes voltage drop in fuel cell (simulation \& modeling), Journal of Electrochimica Acta, 2004.

[6] N. Sammes, Fuel Cell Technology, 2006.

[7] F. Bidault, D.J.L. Brett, P.H. Middleton, N. Abson, N.P. Brandon, A new application for nickel foam in alkaline fuel cells, Journal of Hydrogen Energy, 2009.

[8] M. Schulz, E. Gulzow, G.Steinhilber, Activation of nickel-anode for alkaline fuel cells, Journal of applied surface science, 2001.

[9] G.F. McLean *, T. Niet, S. Prince-Richard, N. Djilali, An assessment of alkaline fuel cell technology, Journal of Hydrogen Energy, 2002.

[10] C. Siegel, Review of computational heat and mass transfer modeling in polymerelectrolyte-membrane (PEM) fuel cells, Journal of Energy, 2008.

[11] J. Holman, Heat Transfer, ninth Edition, 2002.

[12] M.W. Davis, Proposed Testing Methodology and Laboratory Facilities for Evaluating Residential Fuel Cell Systems, 2002.

[13] F. Barbir, Fuel cell stack design principles with concepts of micro-mini fuel cells, 2008.

[14] R.E. Sonntag, C. Borgnakke, G.J. Van Wylen, Fundamentals of Thermodynamics, Sixth edition, 1973.

[15] I. Verhaert, M.D. Paepe, G. Mulder, Thermodynamic model for an alkaline fuel cell, Journal of Power Sources, 2009.

[16] E.A.D. Saunders, Heat Exchangers (Designing for heat transfer), 1988.

[17] Yu. G. Chirkov, V. I. Rostokin, Alkaline fuel cells: calculating and comparing overall currents of hydrophobized cathodes with thin regular-structure and thick stochasticstructure active layers, Russian Journal of Electrochemistry, 2008.

[18] P. Gouérec, L. Poletto, J. Denizot, E. Sanchez-Cortezon, J.H. Miners, The evolution of alkaline fuel cells with circulating electrolyte, Journal of Power Sources, 2004.

[19] X.H. Wang, Y. Chen, H.G. Pan, R.G. Xu, S.Q. Li, L.X. Chen, C.P. Chen, Q.D. Wang, Electrochemical properties of $\mathrm{Ml}(\mathrm{NiCoMnCu})_{5}$ used as an alkaline fuel cell anode, Journal of Alloys and Compounds, 1999.

[20] J.H. JO, S.K. MOON and S.C. YI, Simulation of influences of layer thicknesses in an alkaline fuel cell, Journal of Applied Electrochemistry, 2000. 